\title{
Pattern and Outcome of Self- Poisoning among Adult population Admitted in a Tertiary Care Hospital
}

\author{
Madhabi Karmaker, ${ }^{1}$ Khan Abul Kalam Azad, ${ }^{2}$ Partha Sarathi Sarker, ${ }^{3}$ Noshin Tabassum, ${ }^{4}$ Debashis Mohanta ${ }^{5}$
}

\begin{abstract}
:
Background: Attempted suicide or deliberate self-harm by self-poisoning among adult males and females are a major public health problem to be addressed like any other medical condition. In recent years, patterns of self-poisoning are changing. So it is important to know about the substances used in self poisoning and its outcome.

Materials and Methods: It was a descriptive type of cross sectional study done in Department of Medicine, Dhaka medical college hospital, Dhaka on 100 patients with a history of self poisoning. Study period was six months. A semi structured questionnaire was used for collection of data.

Results: In our study self poisoning was more prevalent among young age group with female preponderance. Family disharmony (45\%) was the commonest cause of self poisoning and most commonly used substance was pharmaceutical drugs. Anxiolytics were the commonest (42\%), organo phosphorus compound (OPC) $20 \%$, mixed drugs $12 \%$, harpic II\%, rat killer $8 \%$, NSAIDs 3\%, Dettol $3 \%$ and Wheel powder $1 \%$. Out of 90 patients $91.11 \%$ patients recovered completely. Death was observed from OPC poisoning.

Conclusion: Knowing the pattern and outcome of self poisoning may improve the community based support system through which we can combat against self- poisoning.
\end{abstract}

Key words: Self - poisoning, tertiary care hospital, pharmaceutical drugs.

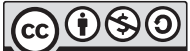

DOI: https://doi.org//0.3329/jom.v2lil.44096

Copyright: (C) 2020 Karmaker M et al. This is an open access article published under the Creative Commons Attribution-NonCommercial-NoDerivatives 4.0 International License, which permits use, distribution and reproduction in any medium, provided the original work is properly cited, is not changed in any way and it is not used for commercial purposes.

Received: 02 May, 2019;

Accepted: 17 August, 2019

\section{Introduction:}

A self-poisoning episode may be defined as the self-exposure of an individual (by ingestion or inhalation) to an amount of substance associated with the significant potential to cause harm. ${ }^{1}$ In Bangladesh Self-poisoning is one of the commonest acute medical presentations. Recent work has however begun to emphasize its importance in the developing world. "The

1. Indoor Medical Officer, Department of Medicine, Dhaka Medical College \& Hospital (DMCH), Dhaka.

2. Professor of Medicine and Principal, Dhaka Medical College; Dean, Faculty of Medicine, University of Dhaka, Dhaka.

3. Indoor Medical Officer, Department of Medicine , $\mathrm{DMCH}$, Dhaka

4. Post-Graduate Trainee, Department of Medicine, DMCH, Dhaka.

5. Registrar, Department of Medicine, ZH Shikder Women's Medical College Hospital, Dhaka.

Corresponding author: Dr. Madhabi Karmaker, Indoor Medical Officer, Dept. of Medicine, Dhaka Medical College Hospital, Dhaka.Email:meru7010@yahoo.com
Global Burden of disease study" reported that 593,000 people killed themselves in the developing world during 1990, 75\% of the world-wide total of deaths from self- harm. ${ }^{2}$ Thus suicide has become a public health concern in many countries among adults ${ }^{3}$. Females are more likely than males to have had suicidal thoughts. ${ }^{4}$ In Bangladesh a recent study demonstrated that $14 \%$ of all deaths amongst $10-50$ year old women were due to poisoning, the majority following suicidal ingestion of pesticides. ${ }^{5}$

\section{Materials and Methods:}

Our study was observational, prospective, hospital based, conducted in 100 patients admitted in medicine department of Dhaka Medical College.The sampling method was purposive and included all adult male and female patients admitted in Medicine units of Dhaka Medical College Hospital with a history of self poisoning who gave written consent.Patients with accidental, homicidal, travel related 
poisoning and who were unwilling to give informed consent by patients or patient's legal guardians were excluded from the study. A semi structured questionnaire was used for collection of data by interviewing patients. Protocol was submitted to Dhaka Medical College ethical committee for approval. Institutional clearance was obtained from the hospital director and the study was conducted over six months of period.

Patients were selected according to inclusion and exclusion criteria. All adult male and female Patients admitted in Medicine units of Dhaka Medical College Hospital with the history of self poisoning who gave written consent were included in the study. Patients with accidental, homicidal, travel related poisoning and those who were unwilling to give written consent were excluded from the study. Patients were evaluated by the investigator, full history was taken and physical examinations were done. After collection of all data, theywere checked, verified for consistency and edited for finalized result. After editing and coding, the coded data directly entered into the computer by using SPSS version 6. Data cleaning validation and analysis was performed using the SPSS/PC software and graph and chart by MS excel. The result was presented in tables in proportion. A "P" value $<0.5$ considered as significant

\section{Results:}

One hundred self-poisoned patients were evaluated. Majority of patients (41\%) belonged to age 20 to 29 years (Table I) with female predominance (63\%) (Table II). Majority comprised of student (37), house wife (21) and service holder (14) (Table III).

Table I: Age distribution of the patients $(n=100)$

\begin{tabular}{lcc}
\hline Age (years) & Number of patients & Percentage \\
\hline$<20$ & 33 & 33 \\
$20-29$ & 41 & 41 \\
$30-39$ & 15 & 15 \\
$40-49$ & 8 & 8 \\
$>50$ & 3 & 3 \\
\hline
\end{tabular}

Table II: Sex distribution of the patients $(n=100)$

\begin{tabular}{lcc}
\hline Sex & Number of Patients & Percentage \\
\hline Female & 63 & 63 \\
Male & 37 & 37 \\
\hline Total & 100 & \\
\hline
\end{tabular}

Table III: Distribution of the patients according to occupation category $(n=100)$

\begin{tabular}{lcc}
\hline Profession & Number of patients & Percentage \\
\hline Service holder & 14 & 14 \\
House wife & 21 & 21 \\
Worker & 12 & 12 \\
Farmer & 3 & 3 \\
Study & 37 & 37 \\
Business & 13 & 13 \\
\hline
\end{tabular}

Regarding the education level of poisoned patients secondary (28\%) and higher secondary (31\%) were the most common group of self-poisoning patient. In this series we also compared the frequency and spectrum of poisoning between adult male and female self-poisoning patients in tertiary level hospital. In female patients majority 22 (34.92\%) were higher secondary level of education. In case of male patients majority were $15(40.54 \%)$ secondary level of education. (Table IV).

Table IV: Distribution of patients by educational level $(n=100)$

\begin{tabular}{lccc}
\hline Educational level & \multicolumn{2}{c}{ Number of patients } & Total \\
& Male $(\mathrm{n}=37)$ & Female $(\mathrm{n}=63)$ & \\
\hline Primary & $5(13.51 \%)$ & $9(14.28 \%)$ & 14 \\
Secondary & $15(40.54 \%)$ & $13(20.63 \%)$ & 28 \\
Higher secondary & $9(24.32 \%)$ & $22(34.92 \%)$ & 31 \\
Graduate & $2(5.40 \%)$ & $7(11.11 \%)$ & 9 \\
Above graduate & $2(5.40 \%)$ & $1(1.58 \%)$ & 3 \\
Others & $3(8.10 \%)$ & $12(19.04 \%)$ & 15 \\
\hline
\end{tabular}

Among all poisoned substances pharmaceutical preparations were the most commonly employed suicidal agents, and were ingested in 57\% of cases. Among these agents Antidepressant/ Anxiolytics (mainly benzodiazepines) were the commonest drugs (42\%) followed by OPC (20\%), mixed drugs (12\%), Harpic (11\%), rat killer (08\%), NSAIDS (03\%) and other household substances like Dettol (03\%), wheel powder (01\%) (Table V).

The majority of patients collected the offending drugs from dispensary (62\%) without prescription, then $27 \%$ from Household member (Table VI). 
Table V: Substances used by self-poisoned patients. $(n=100)$

\begin{tabular}{lcc}
\hline Substances & $\begin{array}{c}\text { Number of } \\
\text { patients }\end{array}$ & $\begin{array}{c}\text { Percentage } \\
(\%)\end{array}$ \\
\hline Antidepressant/ Anxiolytic & 42 & 42 \\
OPC & 20 & 20 \\
Mixed drug & 12 & 12 \\
Harpic & 11 & 11 \\
Ratkiller & 08 & 08 \\
Dettol & 03 & 03 \\
NSAID & 03 & 03 \\
Wheel powder & 01 & 01 \\
\hline
\end{tabular}

Table VI

Source of collection of poisoned substances $(n=100)$

\begin{tabular}{lcc}
\hline Source & $\begin{array}{c}\text { Number of } \\
\text { patients }\end{array}$ & $\begin{array}{c}\text { Percentage } \\
(\%)\end{array}$ \\
\hline Dispensary & 62 & 62 \\
Household member & 27 & 27 \\
Othe $\backslash$ rs & 11 & 11 \\
\hline
\end{tabular}

Nearly half of the patients (43\%) sought medical care within 2 hours. Delay beyond an hour indicated that the patients were at risk of having complications of poisoning. In all cases medical care was asked by their relatives or their guardians. (Table VII)

Table VII

Time interval between poisoning \& treatment seeking $(n=100)$

\begin{tabular}{lcc}
\hline Interval & $\begin{array}{c}\text { Number of } \\
\text { patients }\end{array}$ & $\begin{array}{c}\text { Percentage } \\
(\%)\end{array}$ \\
\hline $0-1 \mathrm{hr}$ & 16 & 16 \\
$1-2 \mathrm{hr}$ & 43 & 43 \\
$2-4 \mathrm{hr}$ & 34 & 34 \\
$4-6 \mathrm{hr}$ & 5 & 5 \\
More than $6 \mathrm{hr}$ & 2 & 2 \\
\hline
\end{tabular}

Study shows family disharmony (45\%) was the commonest background for self-poisoning followed by romantic disappointment $(27 \%)$, circumstance educational (7\%), misunderstanding with parent $(10 \%)$, extramarital relation (4\%) (Table VIII).
Table VIII: Distribution of the study patients according to causal factors $(n=100)$

\begin{tabular}{lccc}
\hline Stressful events & \multicolumn{2}{c}{ Number of patients } & Total \\
& Male $(\mathrm{n}=37)$ & Female(n=63) & \\
\hline Familial disharmony & $25(67.56 \%)$ & $20(31.74 \%)$ & 45 \\
Romantic disappointment $4(10.81 \%)$ & $23(36.50 \%)$ & 27 \\
Educational related & $1(2.70 \%)$ & $6(9.52 \%)$ & 7 \\
Extramarital relation & 0 & $4(6.34 \%)$ & 4 \\
Misunderstanding with & $2(05.40 \%)$ & $8(12.69 \%)$ & 10 \\
parent & & & \\
Preexisting psychiatric & $2(05.40 \%)$ & 0 & 2 \\
illness & & & \\
Unknown & $3(8.10 \%)$ & $2(3.17 \%)$ & 5 \\
\hline
\end{tabular}

Average hospital stay was 1-3 days. We found 10 patients out of 100 were absconded. So we evaluated 90 patients and found 82 patients $(91.11 \%)$ recovered completely. In this study, 5 patients $(5.56 \%)$ recovered partially during hospital stay due to development of intermediate syndrome of OPC poisoning and from corrosive Harpic (Sodium Alkyle benzene sulphonate) poisoning; 3 patients (3.33\%) died of OPC poisoning with history of ingestion of large amount of drug and delayed initiation of treatment. (Table IX). Thus we found several factors affecting the outcomes like type of substances taken, dose of substance, time interval between ingestion and treatment seeking, compliance with treatment etc. We found OPC and corrosive poisoning were related to partial recovery or death while pharmaceutical drug had complete recovery with no death from such poisoning.

Table IX

Hospital Outcome and fate of cases during discharge $(n=90)$

\begin{tabular}{lcc}
\hline Hospital Outcome & Number of patients & Percentage \\
\hline Complete recovery & 82 & $91.11 \%$ \\
Partial recovery & 05 & $05.56 \%$ \\
Death & 03 & $3.33 \%$ \\
\hline
\end{tabular}

\section{Discussion:}

For the purposes of this study, self-poisoning was defined as an act where a person deliberately ingested a poisonous substance, or ingested a medicinal drug or household substances in excess of prescribed dosage, with a fatal outcome. Our analysis involved a total number of 100 respondents, which made an overview of the 
sociodemographic parameters, patterns of suicidal intent, life events, underlying psychiatric illness, and various outcomes among adult self-poisoned patients admitted in tertiary level hospital.

In our study young age group 20-29 yrs was the most common $(41 \%)$ victim of self poisoning, next group of patients (33\%) observed in $<20$ years of age group. All these findings correlate with other study in home and abroad. A large scale study in Bangladesh conducted by Dewan $\mathrm{G}^{6}$ showed that highest number of patients belonged to age group of 21 to 30 years (38.1\%) followed by patients aged under 20 years $(33.8 \%)$. This shows that adolescents and young adults are the most vulnerable population of the country to this kind of poisoning.

In our study, the significant majority of patients attempting self-poisoning were female (63\%), which is nearly equal to a study conducted in a Teaching Hospital Peradeniya, Sri Lanka $^{7}$, where 949 participants were included, of whom $44.2 \%$ were males. Females are thought to be more emotionally labile and they have less alternative, so more frequency of self poisoning among them. This sex ratio contrasted with other international studies which report higher rates of attempted suicide by drug overdoses among female ${ }^{8}$, but was consistent with the reports from other developing countries where the gender ratio for nonfatal self-poisoning by pesticide ingestion is roughly $50 / 50 .{ }^{9}$

However, this gender pattern now appears to be changing in Bangladesh, with more women being admitted to hospital as a result of the ingestions of medicines and other substances,${ }^{10}$ study by Hossain GJ in a tertiary centre of Bangladesh ${ }^{10}$ revealed that females were predominant over males $(77 \%$ versus $23 \%)$ and female to male ratio was $3.3: 1$. The females were found to commit suicide more than male in Bangladesh which is reverse of the figure in majority countries of the globe where males are observed to commit suicide more than females. With increasing urbanization, patterns of self-poisoning in Bangladesh and other South Asian countries may be changing to resemble that of developed countries, accompanied by an increasing proportion of attempted suicides among females. Most patients in this study were from Dhaka city and from surrounding areas.Females had a higher overall level of education, but were significantly less likely to be employed compared to males. Among the all education level of poisoned patients secondary and higher secondarywere the most common group of self poisoning patient. Twenty eight (28\%) of them were secondary school education level and thirty one (31\%) were higher secondary school status and nine $(9 \%)$ were graduate students. As in this period of physical and mental changes occur more profoundly than any age of life. So those mental changes predispose them to self-poisoning.

We found that majority of the patients comprised of student $(37 \%)$, then house wife $(21 \%)$ and service holder (14\%). Findings are similar with other study of Bangladesh like Dewan $\mathrm{G}^{11}$ Occupation was reported in a small series in $\mathrm{DMCH}$ that $18.3 \%$ of patients were student, $16.7 \%$ housewife, $11.7 \%$ businessman, $11.6 \%$ farmer, $1.7 \%$ government employee and $40 \%$ other occupations. In another study, $47 \%$ of patients were farmer, $16 \%$ student and $13 \%$ housewife. ${ }^{12}$

Multiple factors reportedly increase the risk of suicide and self poisoning. Study showed family disharmony (45\%) was the commonest background for self poisoning a finding in accordance with other studies. ${ }^{13,14,15}$ Family disharmony included familial conflict about household activities, decision making about children or other family members, not bearing expenses by husbands etc. Romantic disappointment (27\%) was the next common. This would appear to be an issue particularly with young adult females, a finding in accordance with other studies. ${ }^{13,15}$ Romantic disappointment causes much psychological stress in this population group \& can lead to suicidal ideation or attempts.

$7 \%$ found to have educational circumstances like bad performance in examination; Misunderstanding with parents $(10 \%)$ like quarrel with parents regarding education, mixing with bad people, using and asking for too much money; extramarital relation (4\%). Out of the 100 patients, 2 patients $(2 \%)$ were known to have psychiatric illness (Table 8).This findings quite differ from a study conducted in Australia \& New Zealand, ${ }^{16}$ demonstrated that Suicide has multiple risk factors and associated co morbidities, such as mood disorders, personality disorders, substance misuse and poor physical health. The dissimilarity of these findings in three culturally diverse locations lends weight to the suggestion that even relatively minor conflicts within the family environment can act as a trigger for suicide attempts, perhaps due to the emotional importance placed on these relationships. Suokas et al, $(2001)^{17}$ demonstrated that previously identified risk factors for subsequent suicide following deliberate self-harm include previous self-harm, male gender, older age, psychiatric illness (particularly schizophrenia, depression, bipolar disorder and substancerelated disorders), medical illness and substance misuse. Reith et al, (2004) $)^{18}$ showed that "specifically following deliberate self-poisoning, identified additional risk factors for completed suicide include psychiatric disorders of childhood, male gender, increasing age, more than one previous suicide attempt, living alone, migrant status and being widowed or separated".A comparative study in 
teaching hospital Peradeniya, Sri Lanka ${ }^{19}$ established that Interpersonal conflict is the most common precipitant or immediate trigger prior to the act of non-fatal self poisoningfor example, arguments (with spouse/ parent/other) or problems within a romantic relationship. Females were more likely to report a conflict with parents. Only $3.8 \%(n=35)$ of all those who attempted non-fatal self-poisoning reported severe financial difficulties as the precipitant, but of those who did, males were significantly more likely to identify financial difficulties compared to females. ${ }^{19}$

The substance most commonly ingested for self-poisoning was a pharmaceutical drug. Antidepressant/ Anxiolytics (mainly benzodiazepines) were the commonest drugs (42\%). Next common were OPC (20\%), Mixed drug (12\%), Harpic (11\%), Rat killer (08\%), NSAIDs (03\%), Dettol (03\%) and Wheel Powder (01\%).Findings consistent with other study of home and abroad. Rajapakseet $\mathrm{al}^{49}$ showed that the substance most commonly ingested for non-fatal selfpoisoning was a pharmaceutical drug $(57.1 \%)$ in their study. This result partially follows the result of a study conducted in Japan in 1996 where most common group of drugs involved were benzodiazepines $(32.1 \%)$, followed by neuroleptics $(12.2 \%)$, antidepressants $(10.3 \%)$, analgesics (9.1\%), antihistamines (7.3\%) and barbiturates $(6 \%){ }^{20}$

Another study by Dewan $G^{11}$ showed that pesticide poisoning is a common method of suicide attempt and less commonly accidental poisoning in Bangladesh. Estimated case load of poisoning in hospitals of Bangladesh was 7.1\% (CI 6.9 -7.2) of total admissions. Pesticide poisoning accounted for 39.1\% (CI 37.6-40.6\%) of total poisoning cases admitted in different levels of hospitals in Bangladesh.Most of the offending drugs were collected from dispensary (62\%) without prescription. $27 \%$ drugs were collected from house hold members using those drugs. This follows the result of a study conducted in Bangladesh ${ }^{10}$; where most of the offending drugs were collected from dispensary $(62 \%)$ without prescription. $27 \%$ drugs were collected from house hold members using those drugs.

Nearly half of the patients ( $43 \%$ ) sought medical care within 2 hours. Nearly one fourth patients (34\%) within 4 hour, (16\%) patients within 1 hour and (5\%) patients within 4 to 6 hours. Only (2\%) asked for medical care 6 hours after poisoning. Delay beyond an hour indicated that the patients were at risk of having complications of poisoning. In all cases medical care was asked by their relatives or their guardians. Several factors like transport, decision to bring the patient to hospital, to know that illness was due to poisoning etc. were factors for the time taken by the attendants toillness was due to poisoning etc. were factors for the time taken by the attendants to seek the medical help. Study showed that 10 patients (10\%) were absconded. The reasons of large number of patients who were found to be absconded may be due to social and legal harassment, early and good recovery which made them confidence enough to self release without doctors consultation. In this study, Out of 90 patients 82 patients $(91.11 \%)$ recovered completely. 5 patients $(5.56 \%)$ partially recovered during hospital stay due to intermediate syndrome of OPC poisoning, and from ulceration from harpic poisoning; 3 patients (3.33\%) died of OPC poisoning with history of ingestion of large amount of poison and delayed initiation of treatment

\section{Limitations:}

Our study had several limitations. This study was done only in a tertiary level hospital which may not represent the scenario of the whole country.On the other hand the number of sample taken in this study was small in number and the study period was also short. So we suggest to perform this type of study in district level and Upazilla health complex for better representing result of the country.

\section{Conclusions:}

Early diagnosis and prompt institution of appropriate supportive therapy can make a favorable outcome in poisoning patient. At the same time, mental support from family and friends should be provided for prevention of self poisoning. To prevent high incidence of death rate due to poisoning, facilities for prompt and adequate treatment should be available in all hospitals and all the units of hospital should follow the same 'National guideline' for management. To ensure up-to-date management regular updated training program should be run among health care providers. It would be better if a complete poisoning unit/ toxicology unit could be established in tertiary care hospitals. Though we have less number of psychiatrists, every patient after an attack should get proper psychiatric evaluation. Awareness program also should be arranged about self poisoning. Rules and legislation should be formulated so that nobody can purchase drugs without prescription. Thus by improving the management system and strengthening community based support system, we can combat against self-poisoning.

\section{Conflict of interest: None.}

\section{References:}

1. Camidge DR, Wood RJ \& Bateman DN: The epidemiology of self poisoning in the U. K. Br J Clinical Pharmacology 2003;56(6): 613-619.

2. Murray CJL, Lopez AD. Global Burden of Disease StudySummary. Lancet1997; 349:1269-76. 
3. World Health Organization: 2001 Background of SUPREPrevention of Suicide Behavior. Available from: http:// www.who.int/mental_health/prevention/suicide/background. (Accessed December 2011).

4. Crosby AE, Han B, Ortega LAG, Parks SE, Gfoerer J. Suicidal thoughts and behaviors among adults aged $>18$ years-United States, 2008-2009. MMWR Surveillance Summaries 2011;60:SS-13.

5. Yusuf HR, Akhter HH, Rahman MH, Chowdhury MK, RochatRW. Injury related deaths amongst women aged 1050 years in Bangladesh, 1996-97. Lancet2000;355:1220-4

6. Thunga G, Sam KG, Khera K, Pandey S and Sagar SV. Evaluation of incidence, clinical characteristics and management in organophosphorus poisoning patients in a tertiary care hospital; Journal of Toxicology and Environmental Health Sciences 2010;2(5):73-76.

7. Rajapakse T, Griffiths KM, Christensen H, Cotton S. A comparison of non-fatal self-poisoning among males and females, in Sri Lanka. BMC Psychiatry 2014,14:221.

8. Nguyen TV, Dalman C, Le TC, Nguyen TV, Tran NV, Allebeck P:Suicide attempt in a rural area of Vietnam: Incidence, methods used and access to mental health care. Int J Ment Health Syst 2010,4(1):1-6.

9. Ramdurg S, Goyal P, Sharan P, Goyal S, Sagar R: Sociodemographic profile, clinical factors, and mode of attempt in suicide attempters in consultation liaison psychiatry in a tertiary care center. Ind Psychiatry J 2012;20(1):11

10. Hossain JG. Clinico-Epidemiological Study of Self-poisoning Among Students of Academic Institutes. FCPS Dissertation, 2013.

11. Dewan G. Analysis of Recent Situation of Pesticide Poisoning in Bangladesh: Is There a Proper Estimate? Asia Pac J Med Toxicol 2014;3:76-83.
12. Hasan AN, Haque MM. A Clinical Study to See the Predictive Utility of Glasgow Coma Scale in Acute Organophosphorus Poisoning. Dinajpur Med Col J 2011;4:56-61.

13. Chowdhury FR, Rahman AU, Mohammed FR, Chowdhury A, Ahasan HA, Bakar MA. Acute poisoning in southern part of Bangladesh - the case load is decreasing. Bangladesh Med Res Counc Bull 2011;37:61-5.

14. Jacobsen D, Frederichsen PS, Knutsen KM, Sorum Y, Talseth T, Odegaard OR. Clinical course in acute self poisoning: a prospective study of 1125 consecutively hospitalised adults. Hum Exp Toxicol1984; 3:107-16.

15. Bailas MC, Reid PG, Beck P, et al. Changing patterns of self poisoning in a UK health district. Q J Med1996; 89:893901.

16. Carter G, David M. Reith DM, Whyte M, Pherson M. Repeated self-poisoning: increasing severity of self-harm as a predictor of subsequent suicide. The British Journal of Psychiatry (2005) 186: 253-257 doi: 10.1192/bjp.186.3.253.

17. Suokas, J., Suominen, K., Isometsa, E., et al. Long-term risk factors for suicide mortality after attempted suicide - findings of a 14-year follow-up study. Acta Psychiatrica Scandinavica, 2001;104:117-121.

18. Reith DM, Whyte IM, Carter GL et al. Risk factors for suicide and other deaths following hospital treated self poisoning in Australia. Australian and New Zealand Journal of Psychiatry 2004;38:520-525.

19. Rajapakse T, Griffiths KM, Christensen H, Cotton S. A comparison of non-fatal self-poisoning among males and females, in Sri Lanka. BMC Psychiatry 2014;14:221.

20. Van der Hoek W, Konradsen F, Athukorala K, Wanigadewa T. Pesticide poisoning: a major health problem in Sri Lanka. SocSci Med 1998; 46:495-504. 